\title{
Identification of the Most Affecting Factor and the Most Income Range of the Affected Middle Class Family by Using Fuzzy Matrix
}

\author{
C. Ramkumar and R. Ravanan
}

\begin{abstract}
Nowadays so many middle class families are affected by many different factors like misunderstanding between husband and wife, poor economic status, mental stress, cost of living index, property sharing, unequal educational status between husband and wife, more number of family members, inadequate of family number, joint family, poor health, immoral social relationship, unnecessary expenditure, relations interfere and so on. Here we identify the factor which affecting the middle class family mostly, also we identify the most income range to which the factor is most affected. To study the passenger transportation problem, the matrix theory was developed in the year 1998 by Dr. W.B. Vasantha and V. Indira. Now we use this model to identify the factor which most affected the middle class family and also we identify the income range of the affected families.
\end{abstract}

Keywords--- PID Matrix, RD Matrix, RID Matrix, CEID Matrix, RFD Matrix, CEFD Matrix

\section{The Method of Application of PID Matrix} Very simple but a very effective technique is used on the
collected data of 600 families with different income group and their most affected factor of their family. We take the data as it is and transform into percentage income dependent data matrix by taking along the row the income of the family and along the column the different factors by which they suffer. Using the Raw Data matrix we make it into percentage income dependent data matrix $\left(a_{\mathrm{ij}}\right)$. This matrix represents a data which is totally uniform. At the third stage we estimate the average of every column in the IFD matrix. Using the average $t_{j}$ of each $j^{\text {th }}$ column, we choose a [5] parameter $\alpha$ from the interval $[0,1]$ and form the Refined Income Dependent matrix, [2] using the formula

$$
\begin{aligned}
& \text { if } a_{i j}<\left(t_{j}-\alpha \times \sqrt{\frac{t j}{n}}\right) \text { then } e_{i j}=-1 \\
& \text { else if } a_{i j} \in\left(t_{j}-\alpha \times\right) \text { then } e_{i j}=0 \\
& \text { else if } a_{i j}>\left(t_{j}+\alpha \times \sqrt{\frac{t j}{n}}\right) \text { then } e_{i j}=+1 .
\end{aligned}
$$

We redefined the PID matrix into Refined Income Dependent Fuzzy matrix. For this matrix the entries are $-1,0$, 1. Now the row sum of this matrix gives the main income

C. Ramkumar, Assistant, Professor of Mathematics, Shree Chandraprabhu Jain college, Minjur, Thiruvallur District, Tamilnadu.

R. Ravanan, Associate Professor, Department of Statistics, Presidency college, Chennai, Tamilnadu. range of the middle class family, which is affected by the unidentified factor. We also combine these matrices by varying $\alpha \in[0,1]$, so that we get the combine effective income dependent data matrix.

The row sum is obtained for CEID matrix and conclusion taken by based on the row sum.

To identify the most affecting factor, we use the raw data matrix. Using the average $t_{i}$ of each $i^{\text {th }}$ row. We choose a [5] parameter $\beta$ from $[0,1]$ and form the refined factor dependent matrix, [2] using the formula if $\mathrm{a}_{\mathrm{ij}}<\left(\mathrm{t}_{\mathrm{i}}-\beta \times \sqrt{\frac{t i}{n}}\right)$ then $\mathrm{e}_{\mathrm{ij}}=-1$ else if $\mathrm{a}_{\mathrm{ij}} \epsilon\left(\mathrm{t}_{\mathrm{i}}-\beta \times \sqrt{\frac{t i}{n}}, \mathrm{ti}+\beta \times \sqrt{\frac{t i}{n}}\right)$ then $\mathrm{e}_{\mathrm{ij}}=0 \quad$ else if $\mathrm{a}_{\mathrm{ij}}>\left(\mathrm{t}_{\mathrm{i}}+\beta \times \sqrt{\frac{t i}{n}}\right)$ then $\mathrm{e}_{\mathrm{ij}}=+1$. We redefine the raw matrix into refined factor fuzzy matrix. For this matrix the entries are $-1,0,1$. Now the column sum of this matrix gives the most affecting factor of the middle class family. We also combine these matrices by varying $\beta \in[0,1]$. Hence we get the combined effect factor dependent matrix. The column sum is obtained for CEFD matrix and conclusion is taken by based on the column sums.

\section{DESCRIPTION OF THE PROBLEM}

The middle class family is affected by different factor is common in all over the world. In particularly take 600 middle class families in the Tamilnadu state. These families are suffering by the factors like ill well of inter relationship, unmoral social relationship, unequal educational status, more number of family members and so on. Here we take 15 factors as attributes. Hence we use the effective tool fuzzy matrix [3] to identify the most important affecting factor and also we identify the most range of income of the affected middle class family.

\section{IDENTIFICATION OF THE MOST AFFECTING FACTOR OF THE Most Income Range of THE Middle Class FAMILY BY USING 6 X 15 MATRICES.}

Using the linguistic questionnaire we have taken the following fifteen attributes

$$
\left(\mathrm{X}_{1}, \mathrm{X}_{2}, \mathrm{X}_{3}, \ldots \mathrm{X}_{15}\right)
$$

$X_{1}$ - Misunderstanding between husband and wife. $X_{2}-$ immoral social relationship. $\quad X_{3}-$ unequal education status between husband and wife. $\mathrm{X}_{4}-$ More number of family members. $\mathrm{X}_{5}$ - Inadequate of family members. $\mathrm{X}_{6}-$ Joint family. $X_{7}-$ Poor physical health. $X_{8}-$ Poor business or job. 
$\mathrm{X}_{9}-$ Property sharing. $\mathrm{X}_{10}-$ unnecessary expenditure. $\mathrm{X}_{11}-$ Mental stress. $X_{12}-$ Poor economical status. $X_{13}-$ More savings. $\mathrm{X}_{14}-$ Cost of living index. $\mathrm{X}_{15}-$ Relations interfere.

We have collected 600 data from 600 middle class families with the six different ranges of income as follows 114 families in the income range $4000-6000$. 96 families in the income range $6001-8000$. 95 families in the income range $8001-$ 10,000. 85 families in the income range $10,001-12,000.90$ families in the income range $12,001-14,000.120$ families in the income range $14,001-16,000$.

The income ranges are taken as rows and the affecting factors are taken as columns in the initial raw data matrix.

Initial Raw Data matrix of middle class family of order 6 X 15

\begin{tabular}{|l|l|l|l|l|l|l|l|l|l|l|l|l|l|l|l|}
\hline $\begin{array}{l}\text { Attributes } \\
\text { Income }\end{array}$ & $\mathrm{X} 1$ & $\mathrm{X} 2$ & $\mathrm{X} 3$ & $\mathrm{X} 4$ & $\mathrm{X} 5$ & $\mathrm{X} 6$ & $\mathrm{X} 7$ & $\mathrm{X} 8$ & $\mathrm{X} 9$ & $\mathrm{X} 10$ & $\mathrm{X} 11$ & $\mathrm{X} 12$ & $\mathrm{X} 13$ & $\mathrm{X} 14$ & $\mathrm{X} 15$ \\
\hline $4,000-6,000$ & 14 & 4 & 4 & 12 & 2 & 0 & 4 & 8 & 14 & 1 & 14 & 15 & 0 & 15 & 7 \\
\hline $6,001-8,000$ & 12 & 2 & 3 & 10 & 4 & 2 & 3 & 14 & 2 & 3 & 13 & 12 & 2 & 12 & 2 \\
\hline $8,001-10,000$ & 6 & 4 & 3 & 6 & 12 & 4 & 6 & 3 & 16 & 2 & 6 & 10 & 1 & 10 & 6 \\
\hline $\begin{array}{l}10,001- \\
12,000\end{array}$ & 11 & 2 & 4 & 4 & 3 & 8 & 8 & 9 & 7 & 14 & 4 & 4 & 0 & 4 & 3 \\
\hline $\begin{array}{l}12,001- \\
14,000\end{array}$ & 5 & 3 & 3 & 12 & 16 & 10 & 4 & 3 & 4 & 3 & 8 & 6 & 2 & 8 & 3 \\
\hline $\begin{array}{l}14,001- \\
16,000\end{array}$ & 2 & 2 & 3 & 2 & 12 & 3 & 12 & 3 & 17 & 6 & 16 & 16 & 0 & 12 & 14 \\
\hline
\end{tabular}

Percentage Income Dependent Matrix of middle class family of order 6 X 15

\begin{tabular}{|l|l|l|l|l|l|l|l|l|l|l|l|l|l|l|l|}
\hline $\begin{array}{l}\text { Attributes } \\
\text { Income }\end{array}$ & X1 & X2 & X3 & X4 & X5 & X6 & X7 & X8 & X9 & X10 & X11 & X12 & X13 & X14 & X15 \\
\hline $4,001-6,000$ & 12.28 & 3.5 & 3.5 & 10.52 & 1.75 & 0 & 3.5 & 7.0 & 12.28 & .87 & 12.28 & 13.15 & 0 & 13.15 & 6.14 \\
\hline $6,001-8,000$ & 12.5 & 2.08 & 3.12 & 1.04 & 4.16 & 2.08 & 3.12 & 14.58 & 2.08 & 3.12 & 13.54 & 12.5 & 2.08 & 12.5 & 2.08 \\
\hline $8,001-10,000$ & 6.31 & 4.21 & 3.15 & 6.31 & 12.63 & 4.21 & 6.31 & 3.15 & 16.84 & 2.10 & 6.31 & 10.5 & 1.05 & 10.5 & 6.31 \\
\hline $\begin{array}{l}10,001- \\
12,000\end{array}$ & 12.94 & 2.35 & 4.70 & 4.70 & 3.52 & 9.41 & 9.41 & 10.58 & 8.23 & 16.47 & 4.7 & 4.7 & 0 & 4.7 & 3.52 \\
\hline $\begin{array}{l}12,001- \\
14,000\end{array}$ & 5.55 & 3.33 & 3.33 & 13.33 & 17.77 & 11.11 & 4.44 & 3.33 & 4.44 & 3.33 & 8.88 & 6.66 & 2.22 & 8.88 & 3.33 \\
\hline $14,001-16,000$ & 1.66 & 1.66 & 2.49 & 1.66 & 9.99 & 2.49 & 9.99 & 2.49 & 14.16 & 4.9 & 13.33 & 13.33 & 0 & 9.99 & 11.66 \\
\hline
\end{tabular}

The average of the above PFD matrix

\begin{tabular}{|l|l|l|l|l|l|l|l|l|l|l|l|l|l|l|l|}
\hline Average & 8.54 & 2.85 & 3.38 & 6.26 & 8.30 & 4.80 & 6.12 & 6.85 & 9.67 & 5.13 & 9.84 & 10.14 & 0.89 & 9.95 & 5.50 \\
\hline
\end{tabular}

The RID matrix for $\alpha=0.15$

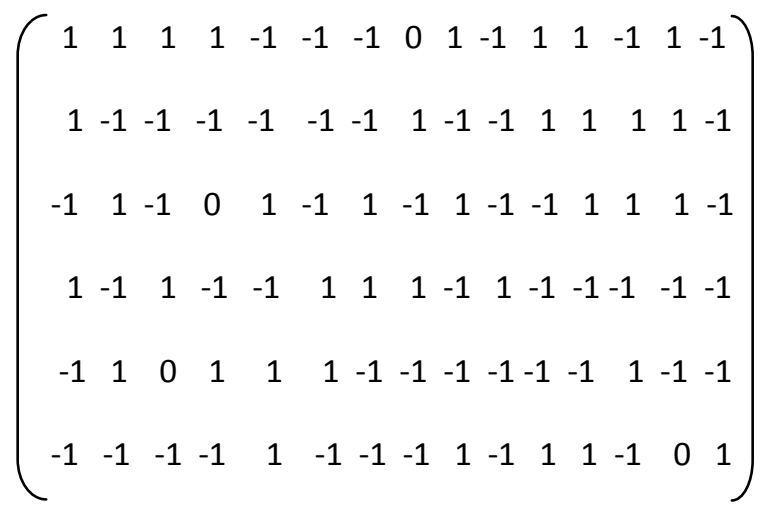

The row sum matrix

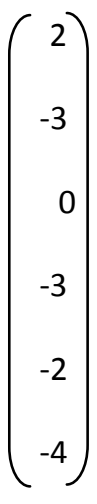


The RID matrix for $\alpha=0.25$

$\left(\begin{array}{ccccccccccccccc}1 & 1 & 0 & 1 & -1 & -1 & -1 & 0 & 1 & -1 & 1 & 1 & -1 & 1 & 1 \\ 1 & -1 & -1 & -1 & -1 & -1 & -1 & 1 & -1 & -1 & 1 & 1 & 1 & 1 & -1 \\ -1 & 1 & -1 & 0 & 1 & -1 & 1 & -1 & 1 & -1 & -1 & 1 & 1 & 1 & 1 \\ 1 & -1 & 1 & -1 & -1 & 1 & 1 & 1 & -1 & 1 & -1 & -1 & -1 & -1 & -1 \\ -1 & 1 & 0 & 1 & 1 & 1 & -1 & -1 & -1 & -1 & -1 & -1 & 1 & 1 & -1 \\ -1 & -1 & -1 & -1 & 1 & -1 & 1 & -1 & 1 & 0 & 1 & 1 & -1 & 1 & 1\end{array}\right)$

The RID matrix for $\alpha=0.4$

$\left(\begin{array}{ccccccccccccccc}1 & 1 & 0 & 1 & -1 & -1 & -1 & 0 & 1 & 1 & 1 & 1 & -1 & 1 & 1 \\ 1 & -1 & 0 & -1 & -1 & -1 & -1 & 1 & -1 & -1 & 1 & 1 & 1 & 1 & -1 \\ -1 & 1 & 0 & 0 & 1 & -1 & 0 & -1 & 1 & -1 & -1 & 0 & 1 & 1 & 1 \\ 1 & -1 & 1 & -1 & -1 & 1 & 1 & 1 & -1 & 1 & -1 & -1 & -1 & -1 & -1 \\ -1 & 1 & 0 & 1 & 1 & 1 & -1 & -1 & -1 & -1 & -1 & -1 & 1 & -1 & -1 \\ -1 & -1 & -1 & -1 & 1 & -1 & 1 & -1 & 1 & 0 & 1 & 1 & -1 & 0 & 1\end{array}\right)$

The CEID matrix

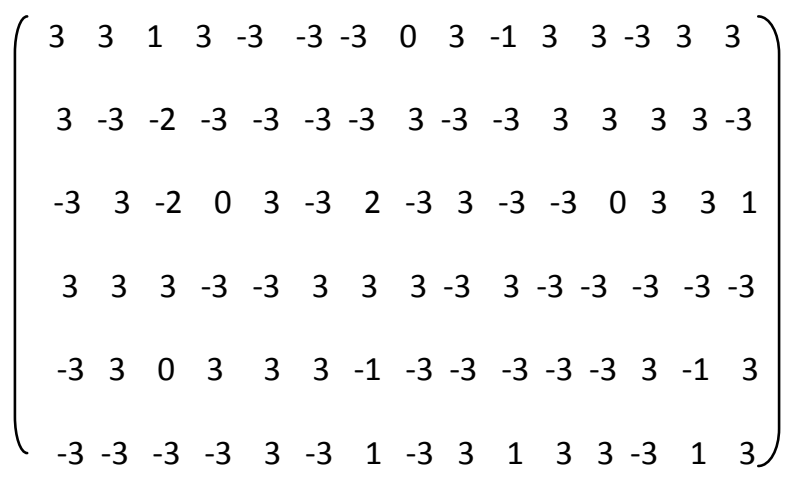

The row sum matrix

$$
\left(\begin{array}{l}
3 \\
-3 \\
2 \\
-3 \\
-2 \\
0
\end{array}\right)
$$

The row sum matrix

$$
\left(\begin{array}{l}
5 \\
-2 \\
1 \\
-3 \\
-4 \\
-1
\end{array}\right)
$$

The row sum matrix

$$
\left(\begin{array}{c}
12 \\
-8 \\
3 \\
-9 \\
-2 \\
-6
\end{array}\right)
$$


The RFD matrix for $\beta=0.15$

$$
\left(\begin{array}{ccccccccccccccc}
1 & -1 & -1 & 1 & -1 & -1 & -1 & 1 & 1 & -1 & 1 & 1 & -1 & 1 & -1 \\
1 & -1 & -1 & 1 & -1 & -1 & -1 & 1 & -1 & -1 & 1 & 1 & -1 & 1 & -1 \\
-1 & -1 & -1 & -1 & 1 & -1 & -1 & -1 & 1 & -1 & -1 & 1 & -1 & 1 & -1 \\
1 & -1 & -1 & -1 & -1 & 1 & 1 & 1 & 1 & 1 & -1 & -1 & -1 & -1 & -1 \\
-1 & -1 & -1 & 1 & 1 & 1 & -1 & -1 & -1 & -1 & -1 & 0 & -1 & 1 & -1 \\
-1 & -1 & -1 & -1 & 1 & -1 & 1 & -1 & 1 & -1 & 1 & 1 & -1 & 1 & 1
\end{array}\right)
$$

Column sum matrix

$\left(\begin{array}{lllllllllllllll}0 & -6 & -6 & 0 & 0 & -2 & -2 & 0 & 2 & -4 & 0 & 3 & -6 & 4 & -4\end{array}\right)$

The RFD matrix for $\beta=0.25$

$$
\left(\begin{array}{ccccccccccccccc}
1 & -1 & -1 & 1 & -1 & -1 & -1 & 1 & 1 & -1 & 1 & 1 & -1 & 1 & -1 \\
1 & -1 & -1 & 1 & -1 & -1 & -1 & 1 & -1 & -1 & 1 & 1 & -1 & 1 & -1 \\
-1 & -1 & -1 & -1 & 1 & -1 & -1 & -1 & 1 & -1 & -1 & 1 & -1 & 1 & -1 \\
1 & -1 & -1 & -1 & -1 & 1 & 1 & 1 & 1 & 1 & -1 & -1 & -1 & -1 & -1 \\
-1 & -1 & -1 & 1 & 1 & 1 & -1 & -1 & -1 & -1 & 1 & 0 & -1 & 1 & -1 \\
-1 & -1 & -1 & -1 & 1 & -1 & 1 & -1 & 1 & -1 & 1 & 1 & -1 & 1 & 1
\end{array}\right)
$$

Column sum matrix $\quad\left(\begin{array}{llllllllllllllll}0 & -6 & -6 & 0 & 0 & -2 & -2 & 0 & 2 & -4 & 2 & 3 & -6 & 4 & -4\end{array}\right)$

$$
\text { The RFD matrix for } \beta=0.4 \quad\left(\begin{array}{ccccccccccccccc}
1 & -1 & -1 & 1 & -1 & -1 & -1 & 1 & 1 & -1 & 1 & 1 & -1 & 1 & -1 \\
1 & -1 & -1 & 1 & -1 & -1 & -1 & 1 & -1 & -1 & 1 & 1 & -1 & 1 & -1 \\
-1 & -1 & -1 & -1 & 1 & -1 & -1 & -1 & 1 & -1 & -1 & 1 & -1 & 1 & -1 \\
1 & -1 & -1 & -1 & -1 & 1 & 1 & 1 & 1 & 1 & -1 & -1 & -1 & -1 & -1 \\
-1 & -1 & -1 & 1 & 1 & 1 & -1 & -1 & -1 & -1 & 1 & 0 & -1 & 1 & -1 \\
-1 & -1 & -1 & -1 & 1 & -1 & 1 & -1 & 1 & 1 & 1 & 1 & -1 & 1 & 1
\end{array}\right)
$$

The Column sum matrix

$\left(\begin{array}{lllllllllllllll}0 & -6 & -6 & 0 & 0 & -2 & -2 & 0 & 2 & -4 & 2 & 3 & -6 & 4 & -4\end{array}\right)$ 
The CEFD matrix

$$
\left(\begin{array}{ccccccccccccccc}
3 & -3 & -3 & 3 & -3 & -3 & -3 & 3 & 3 & -3 & 3 & 3 & -3 & 3 & -3 \\
3 & -3 & -3 & 3 & -3 & -3 & -3 & 3 & -3 & -3 & 3 & 3 & -3 & 3 & -3 \\
-3 & -3 & -3 & -3 & 3 & -3 & -3 & -3 & 3 & -3 & -3 & 3 & -3 & 3 & -3 \\
3 & -3 & -3 & -3 & -3 & 3 & 3 & 3 & 3 & 3 & -3 & -3 & -3 & -3 & -3 \\
-3 & -3 & -3 & 3 & 3 & 3 & -3 & -3 & -3 & -3 & 1 & 0 & -3 & 3 & -3 \\
-3 & -3 & -3 & -3 & 3 & -3 & 3 & -3 & 3 & -1 & 3 & 3 & -3 & 3 & 3
\end{array}\right)
$$

The Column sum matrix

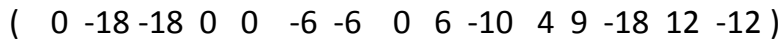

\section{RESULTS AND DisCUSSION}

From the above analysis, we observe that the highest value [4] in the column matrix has not changed with the change of value of the parameter $\alpha$ from 0 to 1 . Hence we infer that its corresponding income range Rs. 4000/- to Rs.6000/- of the family is affected mostly[1]. The Combined Effect Income Dependent matrix also confirms the same. Also we observe that the highest value in the Row matrix has not changed with the change of value of the parameter $\beta$ from 0 to 1 . Hence we infer that its corresponding factor that is the cost of living index has affected the family mostly. The Combined Effect Factor Dependent matrix also confirms the same.

\section{CONCLUSION}

Here we used a very effective fuzzy technique on the collected data of 600 families in Tamilnadu with different income group of the family from Rs.4000/- to Rs. 16,000/- and the affecting factors of the family like Misunderstanding between husband and wife, immoral social relationship, unequal education status between husband and wife, More number of family members, Inadequate of family members, Joint family, Poor physical health, Poor business or job, Property sharing, unnecessary expenditure, Mental stress, Poor economical status, More savings, Cost of living index, Relations interfere. Hence we conclude from the above results and discussion that the middle class family whose income range of Rs 4000/- to Rs 6000/- is affected mostly by the cost of living index.

\section{REFERENCES}

[1] Bellman, R.E., and Zadeh, I.A., "Decision Making in Fuzzy Environment", Management Science 17, Pp. 141 - 164, (1970).

[2] Klir, G.J., and Yuan, B., "Fuzzy sets and Fuzzy logic", Prentice Hall, New Jersey, (1995).

[3] Kosko, B., "Neural Networks and Fuzzy Systems", Prentice Hall, pp118 (2), (2001)

[4] Vasantha Kandasamy. W.B., and Indira, V., "Applications of Fuzzy Cognitive Maps to determine the Maximum Utility of Route", Journal of Fussy Mathematics, published by the International Fuzzy Mathematical Institute 8, Pp. $65-67,(2000)$.

[5] Zimmermann.H.J.,"Fuzzy Set theory and its Application", $2^{\text {nd }}$ Edition Allied Publishing limited, Pp. 1797 - 1818 (12), (1985). 